-Review-

\title{
Mesengenic Potential and Future Clinical Perspective of Human Processed Lipoaspirate Cells
}

\author{
Hiroshi Mizuno and Hiko Hyakusoku \\ Department of Plastic and Reconstructive Surgery, Nippon Medical School
}

\begin{abstract}
The use of stem cells is promising for future cell-based therapy such as tissue regeneration and engineering. Although Embryonic Stem Cells (ESCs) are theoretically highly beneficial, there are some potential limitations of cell regulations and ethical consideration. Mesenchymal Stem Cells (MSCs) isolated from bone marrow stroma have been shown to possess adipogenic, osteogenic, chondrogenic, myogenic and neurogenic potential in vitro. However, bone marrow procurement is severely painful for donors and often requires general anesthesia. Moreover, only small numbers of cells can be harvested.

We previously hypothesized that human adipose tissue obtained from liposuction procedures also contains the same cell population as MSCs, because adipose tissue is mesenchymal in origin, like bone marrow stroma. Subsequent studies revealed that: (1) cell population (which we termed Processed Lipoaspirate [PLA] cells), observed by indirect immunofluorescence study of adipose tissue, consist of cells of mesenchymal origin that have little contamination with endothelial cells, smooth muscle cells and pericytes; (2) these PLA cells exhibit low levels of cell senescence even after multiple passage, as demonstrated by $\beta$ galactosidase staining assay; and (3) PLA cells can differentiate into adipogenic, osteogenic, chondrogenic and myogenic cells in vitro in lineage-specific culture media.

These findings suggest that human PLA might have a mesodermal stem cell population. Since human adipose tissue is plentiful, easily harvested in large quantity under local anesthesia with little patient discomfort, it may be an alternative stem cell source for mesenchymal tissue regeneration and engineering. This review highlights our previous research work on PLA cells and future clinical perspectives, particularly in the field of plastic and reconstructive surgery. (J Nippon Med Sch 2003; 70: 300-306)
\end{abstract}

Key words: adipose tissue, mesodermal stem cells, tissue engineering

\section{Introduction}

The loss of tissue of mesenchymal origin, such as fat, bone, cartilage and muscle, due to trauma, tumor resection or vascular insult represents a significant clinical problem with few solutions. For patients with such problems, autologous tissue transfers have been applied to reconstruct the tissue defects ${ }^{1.2}$, but incumbent donor site morbidity can be both

Correspondence to Hiroshi Mizuno, MD, Department of Plastic and Reconstructive Surgery, Nippon Medical School,

1-1-5 Sendagi, Bunkyo-ku, Tokyo 113-8603, Japan

E-mail: hiromzn@attglobal.net

Journal Website (http://www.nms.ac.jp/jnms/) 
cosmetically and functionally limiting. However, cellbased therapy such as tissue regeneration and engineering may well be useful in treating those suffering from tissue defects or dysfunction.

Two cell types are generally considered as candidates for such strategy: lineage-committed progenitor cells and stem cells. The former have some limitations, the main ones being the low number of cells that can be harvested and the decrease in proliferation potential with increasing donor age $^{3}$. On the other hand, the therapeutic potential of both embryonic stem cells (ESCs) and postnatal stem cells is enormous because of their auto-reproducibility and pluripotentiality. However, there are still some limitations on the practical use of ESCs because of cell regulations and ethical considerations ${ }^{4,5}$. In contrast, postnatal stem cells are by nature immunocompatible, and there are no ethical issues related to their use. Cells obtained from bone marrow stroma, termed Mesenchymal Stem Cells (MSCs), may be the representative cells of this type, possessing adipogenic, osteogenic, chondrogenic, myogenic and neurogenic potential in vitro ${ }^{6-8}$.

We have previously shown that cells obtained from human liposuctioned fat aspirates are also capable of differentiating into adipogenic, osteogenic, chondrogenic and myogenic cells in a lineage-specific culture media; we termed these cells Processed Lipoaspirate (PLA) cells ${ }^{9,10}$. Since human adipose tissue is plentiful, easy to harvest with little patient discomfort and donor site morbidity, it may be an alternative stem cell source for a cell-based therapeutic approach in the future. In this report, a general characterization of PLA cells, including their composition, senescence and potential for differentiation into mesengenic cells, is presented together with a perspective on their future clinical use, particularly in plastic and reconstructive surgery.

\section{General characterization of PLA Cells}

\section{PLA cell processing and preparation}

Human adipose tissue obtained from patients undergoing elective Suction-Assisted Lipectomy
(Liposuction) procedures was processed as described in a previous report to obtain the Processed Lipoaspirate (PLA) cell population ${ }^{9}$. Briefly, the raw liposuctioned aspirates were washed extensively with sterile PBS in order to remove blood cells, saline and local anesthetics. The extracellular matrix was digested with $0.075 \%$ collagenase at $37^{\circ} \mathrm{C}$ for 30 minutes to release the cellular fraction. Collagenase was then neutralized with an equal volume of Dulbecco's Modified Eagle's Medium (DMEM) containing 10\% Fetal Bovine Serum (FBS). The infranatant was centrifuged at $250 \times \mathrm{g}$ for 10 minutes to obtain a high-density PLA cell pellet. The pellet was resuspended in DMEM/10\% FBS, and an Erythrocyte Lysis Buffer $\left(0.16 \mathrm{M} \mathrm{NH}_{4} \mathrm{Cl}\right)$ was added for 10 minutes to lyse contaminating erythrocytes. Following an additional centrifugation step, the PLA cell pellet was resuspended in DMEM/10\% FBS and plated in $100 \mathrm{~mm}$ tissue culture dishes at a density of $1 \times 10^{6}$ cells per plate. Usually, it takes approximately 2 hours for this processing, and 2 to $8 \times 10^{8}$ PLA cells can be obtained from $300 \mathrm{ml}$ of liposuctioned fat aspirates. Subsequently, the PLA cells were maintained in Control Medium (CM: DMEM, 10\% FBS, 1\% antibiotic/antimycotic) at 37 ${ }^{\circ} \mathrm{C}$ and $5 \% \mathrm{CO}_{2}$. The culture medium was changed twice weekly. Confluent PLA cultures (approximately 80\% confluence) were passaged at a ratio of $1: 3$ in trypsin/EDTA. Morphologically, PLA cells exhibited fibroblast-like appearance and expanded easily in the CM (Fig. 1) ${ }^{9}$.

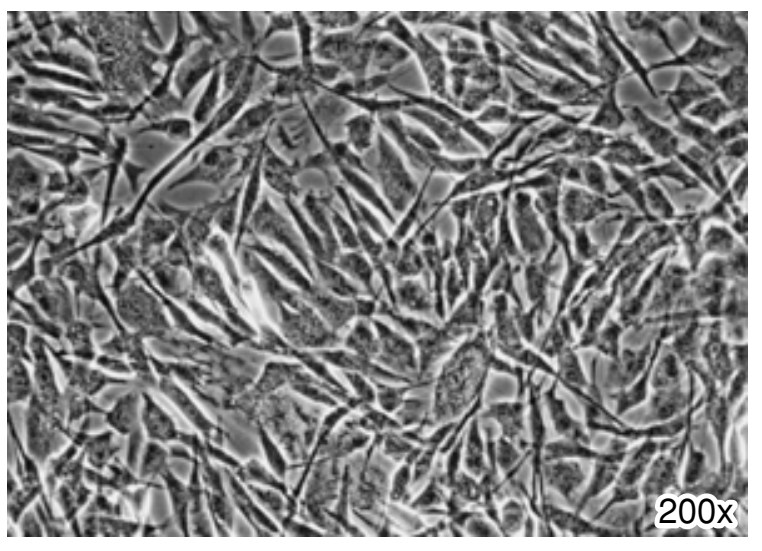

Fig. 1 


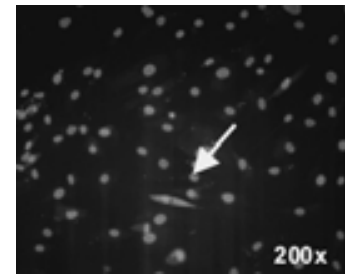

FVIII

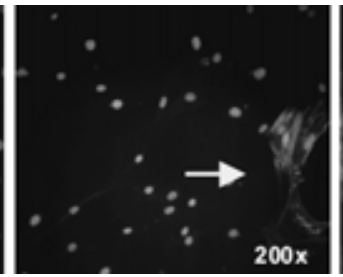

SMA

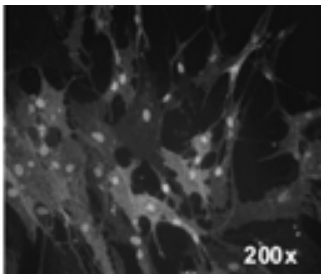

ASO 2

Fig. 2
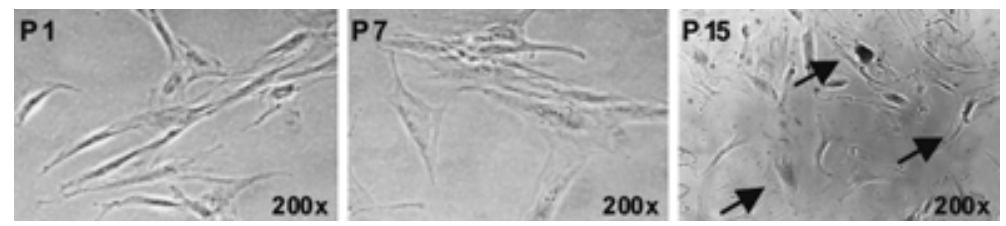

Fig. 3

\section{PLA cell composition}

PLA is considered to be a heterogeneous cell population including endothelial cells, fibroblasts, smooth muscle cells, and preadipocytes ${ }^{11,12}$. To characterize the PLA phenotypically, we examined its composition in an indirect immunofluorescence study. The cell-specific monoclonal antibodies used in this study were as follows:

(1) anti-Factor VIII to identify endothelial cells;

(2) anti-Smooth Muscle Actin to identify smooth muscle cells and pericytes; and

(3) anti-ASO 2 to identify fibroblasts and cells of mesenchymal origin.

These antibodies were subsequently incubated in FITC-conjugated secondary antibody to visualize the positive cells. Cells obtained from human bone marrow stroma were also stained with these same antibodies as a control. As shown in Fig. 2, the majority of the PLA cells were positively stained with anti-ASO 2 antibodies. Moreover, low levels of cells stained with anti-Factor VIII antibodies and anti-Smooth Muscle Actin antibodies were observed in the PLA cells. On the other hand, neither Factor VIII-positive cells nor Smooth Muscle Actin-positive cells were found, although ASO 2-positive cells were found in bone marrow stroma (data not shown). In conclusion, these results suggest that PLA cells are mainly composed of cells of mesenchymal origin with low levels of contamination by endothelial cells, smooth muscle cells and pericytes 9 .

\section{PLA cell senescence assay}

Mesodermal stem cells are pluripotential cells whose progeny give rise to mesodermal tissue while replicating themselves, indicating that they have low levels of cell senescence. To confirm this, cell senescence was assessed with a $\beta$-galactosidase ( $\beta$ gal) staining assay, in which $\beta$-gal activity is present in senescent cells at $\mathrm{pH}$ 6.0. PLA cell samples were stained at each culture passage (passage 1 to 15 ) with $\beta$-gal and then assessed. No positive cells were found in PLA samples in passage 1. Subsequently, positive cell numbers gradually increased as PLA cells were passaged. However, the percentage of $\beta$ gal positive cells remained less than $5 \%$ through passage 10, and was still less than $15 \%$ in passage 15

(Fig. 3). Taken together, these data suggest that PLA cell populations are relatively stable over longterm culture and exhibit low levels of cell senescence ${ }^{9}$.

PLA cell differentiation potential under lineagespecific conditions in vitro

To confirm our hypothesis that putative mesodermal stem cells with the capability of differentiating into mesengenic cells might exist in PLA, PLA samples of passage 1 were cultured in the lineage-specific medium shown in Table $\mathbf{1}$, as 
Table 1 Lineage-Specific Differential Medium with Media Supplementation

\begin{tabular}{|c|c|c|c|}
\hline $\begin{array}{l}\text { Differential } \\
\text { Medium }\end{array}$ & Medium & Serum & Supplementation \\
\hline Control & DMEM & $10 \% \mathrm{FBS}$ & none \\
\hline $\begin{array}{l}\text { Adipogenic } \\
\text { Medium (AM) }\end{array}$ & DMEM & $10 \% \mathrm{FBS}$ & $\begin{array}{l}0.5 \mathrm{mM} \text { isobutyl-methylxanthine (IBMX), } 1 \mathrm{uM} \text { dex- } \\
\text { amethasone, } 10 \mathrm{mM} \text { insulin, } 200 \mathrm{uM} \text { indomethacin, } 1 \% \\
\text { antibiotic/antimycotic }\end{array}$ \\
\hline $\begin{array}{l}\text { Osteogenic } \\
\text { Medium (OM) }\end{array}$ & DMEM & $10 \% \mathrm{FBS}$ & $\begin{array}{l}0.1 \mathrm{uM} \text { dexamethasone, } 50 \mathrm{uM} \text { ascorbate-2-phosphate, } \\
10 \mathrm{mM} \beta \text {-glycerophosphate, } 1 \% \text { antibiotic/antimycotic }\end{array}$ \\
\hline $\begin{array}{l}\text { Chondrogenic } \\
\text { Medium (CM) }\end{array}$ & DMEM & $1 \% \mathrm{FBS}$ & $\begin{array}{l}6.25 \mathrm{ug} / \mathrm{m} l \text { insulin, } 10 \mathrm{ng} / \mathrm{m} l \mathrm{TGF} \beta 1,50 \mathrm{nM} \text { ascorbate- } \\
\text { 2-phosphate, } 1 \% \text { antibiotic/antimycotic }\end{array}$ \\
\hline $\begin{array}{l}\text { Myogenic } \\
\text { Medium (MM) }\end{array}$ & DMEM & $\begin{array}{l}10 \% \mathrm{FBS}, \\
5 \% \mathrm{HS}\end{array}$ & $50 \mathrm{uM}$ hydrocortisone, $1 \%$ antibiotic/antimycotic \\
\hline
\end{tabular}

DMEM; Dulbecco's Modified Eagle's Medium FBS; Fetal Bovine Serum HS; Horse Serum

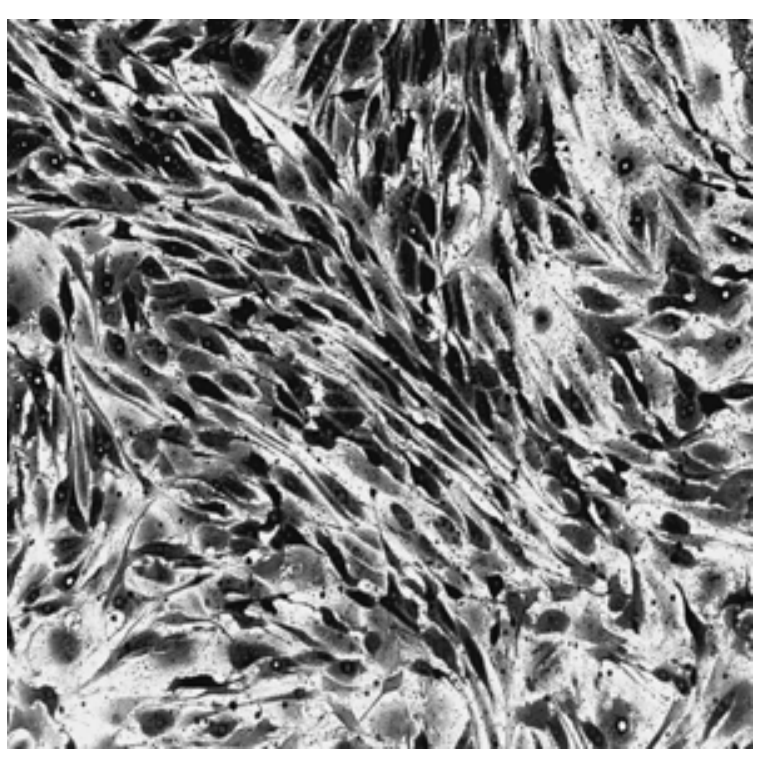

Fig. 4

described in previous literature ${ }^{9}$. At several time points after incubation in the differentiating medium, all samples were assessed morphologically, histologically and immunohistochemically. Commercially available MSCs and lineage-committed progenitor cells were served as positive controls, while PLA incubated in the CM and Human Foreskin Fibroblasts (HFF) incubated in the differentiation medium served as negative controls.

Firstly, PLA cells incubated in Adipogenic Medium (AM) for 2 weeks exhibited intracellular lipid accumulation which was stained positively with Oil Red-O(Fig. 4). Lipid droplets expanded in the cytosol, which is consistent with the phenotype of mature adipocytes. On the other hand, no lipid droplets were observed in either PLA in the CM or HFF in the AM (data not shown). This result indicates that PLA cells undergo adipogenic differentiation.

Secondly, PLA cells incubated in Osteogenic Medium (OM) for 2 weeks formed an extensive network of dense, multilayerd nodules in extracellular matrices (ECM) stained positively for alkaline phosphatase (Fig. 5). Furthermore, PLA cells incubated in $\mathrm{OM}$ for 4 weeks formed monolayered calcified ECM stained positively for Von Kossa (Fig. 5). These findings strongly suggest that PLA cells are capable of osteogenesis.

Thirdly, we investigated whether PLA cells could be differentiated into chondrogenic cells using a micromass culture technique ${ }^{13}$. Condensed PLA nodules cultured in Chondrogenic Medium (CM) for only 2 days formed a spheroid structure which was approximately $1 \mathrm{~mm}$ in diameter and stained positively for Alcian Blue (which detects sulphated proteoglycans) at $\mathrm{pH} 1.0$ (data not shown). A paraffin section of the PLA spheroid incubated in CM for 2 weeks was also stained positively for Alcian Blue at pH 1.0 (Fig. 6). In addition to Alcian Blue staining, these sections were also stained positively with Goldner's trichrome, which detects collagen matrices, and with monoclonal antibodies for type II collagen, which is specific for cartilagenous matrices

(Fig. 6). These results strongly suggest that PLA cells possess the capability of differentiating toward the chondrogenic lineage. 


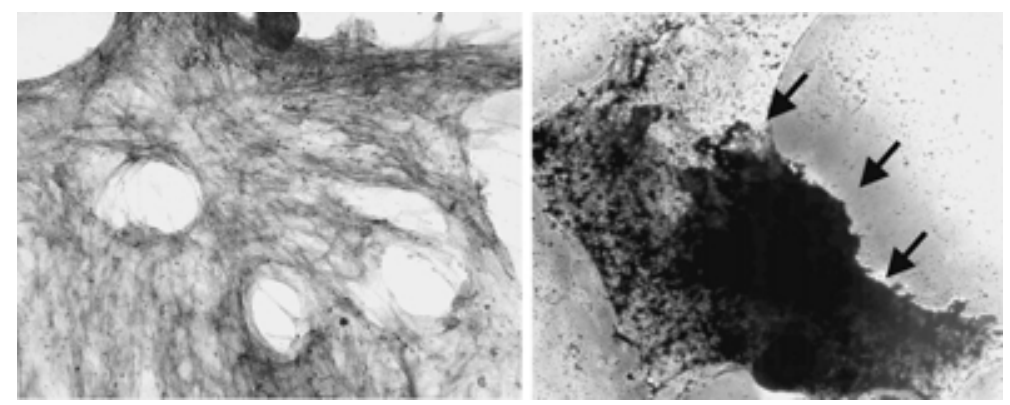

Fig. 5
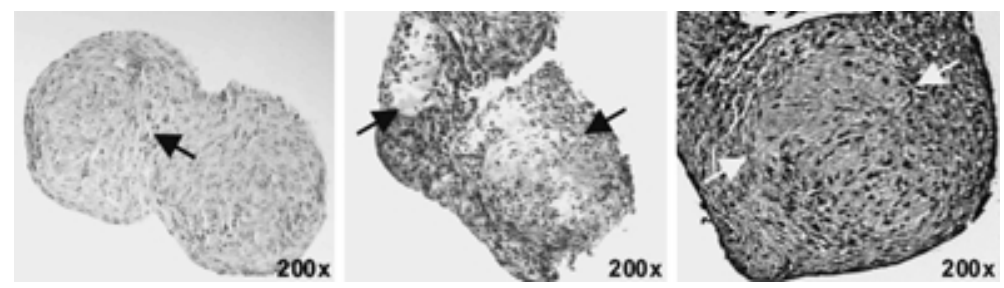

Fig. 6
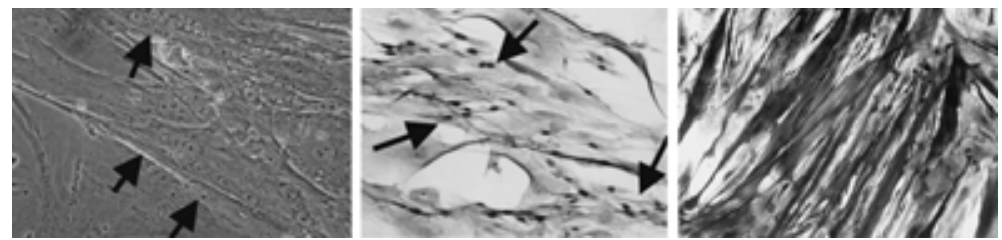

Fig. 7

Finally, after 3 weeks of incubation in Myogenic Medium (MM), tiny longitudinal multinucleated cells were observed morphologically in the PLA cells. Subsequently, these cells fused together and increased in size after 6 weeks of incubation in MM

(Fig. 7). Moreover, immunohistochemical analysis using human skeletal muscle specific antibodies for MyoD 1, which is one of the myogenic regulatory factors, existed in the nuclei, and a myosin heavy chain, which is the contractile protein in the cytosol, showed that both were expressed in PLA cells incubated in MM for 1 to 6 weeks and 3 to 6 weeks, respectively (Fig. 7 ). In addition, RT-PCR analysis using mRNA obtained from total cells incubated in MM showed that the gene expression of both MyoD 1 and the myosin heavy chain were consistent with the results of the immunohistochemical staining (data not shown $)^{10}$.

Taken together, the above findings strongly suggest that pluripotent mesodermal stem cells might exist in human PLA cells.

\section{Clinical perspective of PLA cells}

Since the early $1990 \mathrm{~s}$, cell-based therapies such as tissue regeneration and engineering have been developed experimentally for application to various disorders against which present medical and surgical therapies are either ineffective or impractical. To date, particularly in the field of plastic and reconstructive surgery, autologous tissue transfer has contributed to the treatment of many cases in which mesodermal tissue such as bone, cartilage and muscle defects are critical ${ }^{1,2}$. For example, patients who underwent finger or hand amputation due to trauma or tumor resection used not to be treated successfully. But the progress of microsurgical techniques and immunosuppressive 
reagents offered autologous tissue replantation and allogenic tissue transplantation, respectively ${ }^{14,15}$. Although these procedures are both beneficial, they are sometimes not applied because of severe damage to the amputated tissue or donor tissue shortage. In addition, autologous tissue transfer usually results in severe donor site morbidity, even though transplantation itself is completely successful. In such cases, we can look forward to the clinical application of engineered fingers and hands, as described by Vacanti et $\mathrm{al}^{16}$.

Some of the representative tissue to be regenerated or engineered for plastic and reconstructive surgery may include skin and tissue of mesodermal origin. In this review, however, only mesodermal tissue engineering with or without stem cells is highlighted. Firstly, adipose tissue engineering is promising for breast reconstruction in patients undergoing mastectomy for breast cancer or contour defects due to craniofacial microsomia, trauma and aging. The strategy may include: (1) implantation of adipose tissue engineered in vitro using cells and scaffolds; and (2) in situ adipose tissue engineering after injection of cells and scaffolds ${ }^{17}$. Although both strategies may be useful, they should be selected according to the size of the tissue to be reconstructed. Secondly, supportive tissue including bone and cartilage is also important for the treatment of these defects due to congenital anomalies such as microtia and acquired disorders such as trauma or tumor resection. Other investigators have demonstrated that polyglyocolic acid (PGA) with poly-L-lactic acid (PLLA) and polylactic-co-glycolic acid (PLGA) polymers are available as ideal scaffolds for this supportive tissue ${ }^{18}$. To date, the above strategies have been experimentally and clinically applied with mature cells or lineagecommitted progenitor cells. However, these engineering strategies may theoretically be used with non-induced PLA cells or those induced towards adipogenic, osteogenic or chondrogenic lineage.

In order to apply these strategies in a clinical setting, there are still some difficulties to be considered and overcome. Firstly, angiogenesis or neovascularization into the engineered tissue is necessary for their survival in the body. Particularly, sufficient blood supply with nutrients is essential for three-dimensional large-volume tissue. Currently there are some experimental challenges to reconstruct new vessels and capillary networks in the created tissue and organs, which include the control release of vascular endothelial growth factor

(VEGF) and the three-dimensional endothelial cell culture technique in a collagen scaffold ${ }^{1920}$. Secondly, the development of optimal scaffolds is important for cell growth and structural maintenance of the tissue. As mentioned above, biodegradable synthetic polymers are currently used as scaffolds for bone and cartilage engineering. Collagen gel or fibrin gel may also be candidates as scaffolds for adipose tissue engineering. Obviously, scaffolds must be sterile, biodegradable, easy to handle and easily invaded by cells or growth factors. However, there is still room for improvement when it comes to cell proliferation and differentiation. For example, scaffolds can be designed to release growth factors that induce cellular differentiation and tissue growth in vitro, or cell migration into the wound site in vivo ${ }^{21}$. As biomaterial research goes on, these issues should be overcome in the future.

The use of stem cells including ESCs and adult stem cells is promising. Adult stem cells especially are potentially the best candidate, as long as their origin is autologous tissue to avoid both ethical issues and immunological considerations. The harvesting of adipose tissue to obtain PLA cells is technically easy through liposuction procedures, produces little donor site morbidity and little patient discomfort, and is devoid of ethical considerations. Therefore, we believe that human adipose tissue may be an ideal source of stem cells which can be applied for future mesodermal tissue regeneration and engineering.

\section{Summary and future directions}

While there are still many important issues to be solved, tissue engineering has been advancing rapidly through a multidisciplinary approach including biology, surgery and chemical engineering. Currently, many engineering approaches are being 
attempted to create the appropriate tissue and organ. But different methods are needed to quantitatively assess the long-term outcome of engineered tissue. In any case, we can look forward to the success of this tremendous technology, which offers great functional and cosmetic benefits.

Acknowledgement: The authors would like to thank Dr. Marc H. Hedrick, Associate Professor, Division of UCLA Plastic and Reconstructive Surgery, for his excellent advice and encouragement.

\section{References}

1. Taylor GI, Miller GD, Ham FJ: The free vascularized bone graft. A clinical extension of microvascular techniques. Plast Reconstr Surg 1975; 55: 533-544.

2. Harii K, Ohmori K, Torii S: Free gracilis muscle transplantation, with microvascular anastomoses for the treatment of facial paralysis. Plast Reconstr Surg 1976; 57: 133-143.

3. Schultz E, Lipton BH: Skeletal muscle satellite cells: changes in proliferation potential as a function of age. Mech Ageing Dev 1982; 20: 377-383.

4. Young FE: A time for restraint. Science 2000; 287: 1424.

5. Lenoir N: Europe confronts the embryonic stem cell research challenge. Science 2000; 287: 1425-1427.

6. Pittenger MF, Mackay AM, Beck SC, et al. Multilineage potential of adult human mesenchymal stem cells. Science 1999; 284: 143-147.

7. Ferrari G, Cusella-De Angelis G, Coletta M, et al. Muscle regeneration by bone marrow-derived myogenic progenitors. Science 1998; 279: 1528-1530.

8. Woodbury D, Schwarz EJ, Prockop DJ, et al. : Adult rat and human bone marrow stromal cells differentiation into neurons. J Neurusci Res 2000; 61: 364-370.

9. Zuk PA, Zhu M, Mizuno H, et al. : Multi-lineage cells from human adipose tissue: implication for cell-based therapies. Tissue Eng 2001; $7: 211-228$.

10. Mizuno H, Zuk PA, Zhu M, et al.: Myogenic differentiation by human processed lipoaspirate cells. Plast Reconstr Surg 2002; 109: 199-209.

11. Pettersson P, Cigolini M, Sjostrom L, et al. : Cells in human adipose tissue developing into adipocytes. Acta Med Scand 1984; 215: 447-451.

12. Hauner H, Schmid P, Pfeiffer EF: Glucocorticoids and insulin promote the differentiation of human adipocyte precursor cells into fat cells. J Clin Endocrinol Metabol 1987; 64: 832-835.

13. Denker AE, Nicoll SB, Tuan RS: Formation of cartilage-like spheroids by micromass cultures of murine C3H10T1/2 cells upon treatment with transforming growth factor beta-1. Differentiation 1995; 59: 25-34.

14. Masuhara K, Tamai S, Fukunishi H, et al. : Experience with reanastomosis of the amputated thumb. Seikei Geka 1967; 18: 403-404.

15. Cendales LC, and 3 rd. BWC: Hand transplantation. Hand Clin 2001; 17: 499-510.

16. Vacanti CA, Bonassar LJ, Vacanti MP, et al.: Replacement of an avulsed phalanx with tissueengineered bone. N Engl J Med 2001; 344: 1511-1514.

17. Griffith LG, Naughton G: Tissue engineeringcurrent challenges and expanding oppotunities. Science 2002; 295: 1009-1014.

18. Isogai N, Landis W, Kim TH, et al. Formation of phalanges and small joints by tissue-engineering. J Bone Joint Surg Am 1999; 81: 306-316.

19. Mooney DJ, Mikos AG: Growing new organs. Sci Am 1999; 280: 60-65.

20. Walgenbach KJ, Voigt $\mathrm{M}$, Riabikhin $\mathrm{AW}$, et al. Tissue engineering in plastic and reconstructive surgery. Anat Rec 2001; 263: 372-378.

21. Mahoney MJ, Saltzman WM: Transplantation of brain cells assembled around a programmable synthetic microenvironment. Nat Biotechnol 2001; 19: 934-939.

(Received, November 18, 2002)

(Accepted, January 10, 2003) 